\title{
Role of IOS in Assessing the Improvement of Obstructive Component in Moderate to Severe Obstructive Sleep Apnea Hypopnea Syndrome
}

\author{
${ }^{1}$ Ravi Dosi, ${ }^{2}$ Arpit Jain, ${ }^{3}$ Priyanshu Jain, ${ }^{4}$ Satish Motiwale, ${ }^{5}$ Prakash Joshi
}

\begin{abstract}
Introduction: Impulse oscillometry (IOS), a simple, noninvasive method using the forced oscillation technique, requires minimal patient cooperation and is suitable for use in both children and adults. This method can be used to assess obstruction in the large and small peripheral airways.
\end{abstract}

Aim: To study impulse oscillometry measurements in cases of moderate to severe sleep apnea.

Materials and Methods: A study was performed in Department of Respiratory Medicine, Sri Aurobindo Institute of Medical Sciences. Thirty patients diagnosed with severe sleep apnea underwent home noninvasive ventilation therapy. Pre- and post treatment noninvasive ventilation (NIV) impulse oscillometry was given to these patients.

Results: The pre-NIV spirometry showed predominant mixed pattern of disease with Impulse oscillometry showing reduced R25 and R5 levels. Post 3 months of noninvasive ventilation therapy with $>80 \%$ compliance demonstrated improvement in R25 parameters.

Conclusion: Respiratory resistance and reactance measured by Impulse oscillometryare abnormal in preobese and obese obstructive sleep apnea hypopnea syndrome (OSAHS) patients, and these parameters are closely correlated with OSAHS severity. Impulse oscillometrymight be a useful screening tool for detecting OSAHS in clinic based populations.

Keywords: IOS, NIV, OSAHS, Spirometry.

How to cite this article: Dosi R, Jain A, Jain P, Motiwale $S$, Joshi P. Role of IOS in Assessing the Improvement of Obstructive Component in Moderate to Severe Obstructive Sleep Apnea Hypopnea Syndrome. Indian Sleep Med 2018;13(2):25-28.

Source of support: Nil

Conflict of interest: None

\footnotetext{
${ }^{1}$ Assosciate Professor, ${ }^{2} 3$ rd Year MD Resident, ${ }^{3}$ 2nd Year MD Resident, ${ }^{4} \mathrm{HOD},{ }^{5}$ Consultant

${ }^{1-5}$ Dept of Respiratory Diseases, Sri Aurobindo Institute of Medical Sciences, Medical College and Postgraduate Institute, Indore, Madhya Pradesh

Corresponding Author: Priyanshu Jain, 2nd Year MD Resident, Dept of Respiratory Diseases, Diseases, Sri Aurobindo Institute of Medical Sciences, Medical College and Postgraduate Institute, Indore, Madhya Pradesh, e-mail : jain.priyanshu14@ gmail.com
}

\section{INTRODUCTION}

Obstructive sleep apnea (OSA) is a common disorder characterized by a repetitive collapse of the pharyngeal airway during sleep. It manifests as reduced (hypopnea) or absent (apnea) airflow, despite ongoing inspiratory efforts, which is terminated by a transient arousal from sleep and restoration of upper-airway patency. ${ }^{1,2}$ Consequently, this pathophysiological process causes disturbances in blood gases and sleep structure and has also been associated with cardio-cerebrovascular complications. ${ }^{3-5}$

Nocturnal polysomnography (PSG) is a gold standard method for diagnosing OSA. However, in a country like India PSG is very expensive and time-consuming. There is a high prevalence of OSA and the associated syndrome (OSAHS) in obese populations, yet few centers can afford to perform the diagnostic procedure on all patients presenting with OSA. In this context, simpler and less expensive tests are needed, increased pharyngeal airway collapsibility during expiration plays an important role in these patients, ${ }^{6,7}$ it is expected that the cycle of obstruction and restoration of upper-airway patency from arousal will be accompanied by large change in intrathoracic pressure and in the mechanical properties of the respiratory system.

The improvised technique that uses multiple sound frequencies at one time is called the IOS. The impulses generated by the loudspeaker travel superimposed upon the normal tidal breathing through the large and small airways. Higher frequencies $(>35 \mathrm{~Hz}$ ) travel shorter distances (generally up to the large airways), while lower frequencies $(<15 \mathrm{~Hz})$ travel deeper into the lung and reach the small airways and lung parenchyma.

The caliber of both pharyngeal airway and intrathoracic airways in OSA patients are commonly prone to collapse on the exhale, due primarily to decrease in lung volumes. The cross-sectional area of pharyngeal airway and peripheral airways are known to vary significantly with changes in lung volume. The lumen size in those structures are proved to a decrease when the end-expiratory lung volume (EELV) or FRC are artificially lowered, that either caused by negative expiratory pressure (NEP) or by positive extrathoracic pressure on exhalation, and 
manifests as expiratory flow limitation (EFL) in the both structures as well as airflow resistance are markedly increased. ${ }^{8-11}$ Such a change in lung volume may facilitate pharyngeal airway and intrathoracic airways to collapse or even closure, due to loss effects of caudal traction tension on both structures, and contribute to resistance increase in the airways.

We hypothesized some parameters of IOS measured in OSA patients, such as respiratory resistance at $25 \mathrm{~Hz}$ R25, $\mathrm{R} 5$, and reactance $X$ at $5 \mathrm{~Hz}$ were significantly correlated with OSA severity as defined by AHI. ${ }^{12}$

The aim of this study was to develop a screening tool to see the improvement in obstructive component in moderate to severe OSAHS where polysomnography cannot be performed on a regular basis.

\section{MATERIALS AND METHODS}

The study was done in Department of Pulmonary Medicine, Sri Aurobindo Institute of Medical Sciences, Indore. In total, 30 OSA patients with a body mass index (BMI) greater than $25 \mathrm{~kg} / \mathrm{m}^{2}$ were included in our study. Exclusion criteria were a history of any ongoing cardiac, liver and renal disease, pulmonary hypertension, alcoholism and evidence of any neuromuscular disorder were also excluded.

\section{Sleep Studies}

Overnight sleep studies were performed in all participants, and consisted in full laboratory PSG including electroencephalography (C4-A1, C3-A2), right and left electrooculography, chin electromyography, oronasal airflow, thoracic and abdominal movements (inductive plethysmography bands) and oxygen saturation monitored via a finger probe. Respiratory events were defined as follows: ${ }^{13}$ a nasal pressure drop to $\geq 30 \%$ of baseline and associated with $\geq 3 \%$ desaturation, lasting for at least $10 \mathrm{~s}$ was scored as hypopnea or associated with an EEG arousal was scored as respiratory effortrelated arousals (RERAs). Absence of airflow on a nasal pressure transducer and $<10 \%$ baseline fluctuations on a thermistor signal lasting for $>10 \mathrm{sec}$, was scored as apnea. Respiratory disturbance index (RDI) was calculated by dividing the total apneas, hypopnea, RERAs by the total sleep time in hours, a RDI $15 / \mathrm{h}$ of sleep was used to define the presence of obstructive sleep apnea syndrome (OSAS) ${ }^{13}$ and was used as the gold standard in the evaluation of the operating characteristics of the IOS parameters obtained to detect OSAS.

\section{Spirometry and IOS}

Three maximal flow-volume loops were obtained in the seated position using a MasterScreen pneumotachograph (Jaeger®, Germany), with the largest retained to calculate the first second of forced expiration $\left(\mathrm{FEV}_{1}\right) /$ forced vital capacity (FVC) ratio, $\mathrm{FEV}_{1}$, FVC.

IOS (Jaeger $\left.{ }^{\circledR}\right)$ measurements were made while a technician supported the cheeks of subjects who were wearing nose-clips in the sitting position, fulfilling standard recommendations. ${ }^{14}$ Impulse signals originated from a generator at intervals of $0.2 \mathrm{sec}$, and the rectangular pressure impulses are superimposed on airflow, which are feed to the airway during tidal breathing via a mouthpiece after stable spontaneous volume and airflow were confirmed and a minimum of three consecutive measurements of $>30 \mathrm{sec}$ were taken. As results of IOS measurement, we used the parameters of, mean whole-breath values of Rrs at $5 \mathrm{~Hz}, 25 \mathrm{~Hz}$, and Xrs at $5 \mathrm{~Hz}$ (R5, R25 and X5).

\section{Statistical Analysis}

All analyses were performed using SPSS software. Differences of anthropometry (age, height, weight, $\mathrm{BMI}$ ), lung volume and function were assessed by using one-way analysis of variance (ANOVA). Correlations between IOS measurements in both the positions and RDI and BMI were evaluated using Spearman's rank correlation coefficients. The sensitivity and specificity of possible cut-off points for the parameters of IOS obtained.

\section{RESULTS}

In total, 30 patients who had a BMI $>25.1 \mathrm{~kg} / \mathrm{m}^{2}$ were included in the study, Anthropometric characteristics, lung function and volume data, and PSG data of all patients are summarized in Table 1 . Thirty subjects with a RDI 15 events/h were identified as OSAHS patients. No significant differences were found with respect to age, height, sex, $\mathrm{FEV}_{1} / \mathrm{FVC}$, and lung volume data. Spearman's rank correlation analysis was used to assess the association between IOS measurements and RDI, and BMI . After giving NIV therapy both investigations (IOS and PFT) were performed in all the patients, after comparing the results of investigations we concluded that IOS have shown significant improvement in obstructive component whereas PFT failed to demonstrate any improvement (Tables 2 and 3).

Table 1: Anthropometric Data

\begin{tabular}{lcc}
\hline Parameter & Male & Female \\
\hline Number & 22 & 8 \\
Age $($ years $)$ & $48(+/-15)$ & $45(+/-9)$ \\
Height $(\mathrm{cm})$ & $166(+/-9)$ & $155(+/-5)$ \\
Weight $(\mathrm{kg})$ & $94(+/-18)$ & $88(+/-12)$ \\
BMI $\left(\mathrm{kg} / \mathrm{m}^{2}\right)$ & $34.94(+/-9)$ & $32.1(+/-9)$ \\
Smokers & 11 & 2 \\
Osahs mild & 15 & 5 \\
Osahs moderate & 13 & 4 \\
Osahs severe & 9 & 4 \\
\hline
\end{tabular}


Table 2: Moderate to severe OSA-IOS

\begin{tabular}{lccc}
\hline & Pre NIV & Post NIV & Significance \\
\hline "R' Resistance $(\mathrm{kPa} /$ & $104.9+/-11$ & $76.1+/-6$ & $\mathrm{p}<0.5$ \\
(L/s)) & & & \\
R5 & & & \\
R25 & $168.6+/-18$ & $158.6+/-18$ & $\mathrm{p}<0.01$ \\
"X" Reactance & $4260.2+/-$ & $3210.2+/-523$ & $\mathrm{p}<0.01$ \\
(kPa/L/s) & 523 & & \\
X5 & & & \\
X25 & $29+/-54$ & $29+/-54$ & $\mathrm{p}<0.3$ \\
"AX" Area of & $1.24+/-2.3$ & $1.24+/-2.3$ & $\mathrm{p}<0.6$ \\
$\begin{array}{l}\text { Reactance } \\
\text { (kPa/L) }\end{array}$ & & & \\
\hline
\end{tabular}

Table 3: Moderate to severe OSA-PFT

\begin{tabular}{lccc}
\hline Spirometry & Pre NIV & Post NIV & $p$ value \\
\hline No. of subjects & 30 & 30 & \\
FVC, percent predicted & $74.5 \pm 3.6$ & $71.5 \pm 3.6$ & $<0.6$ \\
FEV & $69.6 \pm 0.9$ & $73.9 \pm 0.9$ & $<0.8$ \\
FEF25-75\%, percent & $61.6 \pm 4.7$ & $71.6 \pm 4.7$ & $<0.8$ \\
predicted & & & \\
PEF, percent & $75 \pm 6.0$ & $85 \pm 6.0$ & $<0.6$ \\
\hline
\end{tabular}

\section{DISCUSSION}

In this study, we systematically appraised the ability of IOS parameter in assessing the improvement of the obstructive component of OSA in moderate to severe OSAHS compared with full polysomnography, for the detection of OSAHS. These associations were stronger when the IOS parameters were obtained, and a highly significant association was found between R25 and RDI $(\mathrm{p}<0.01)$.

We demonstrated that central-airway parameter measurements by IOS in pre- and post-NIV patients were significantly and moderately correlated with the severity of OSAHS as defined by RDI (Table 2). These associations strongly found that significant resistance R25 value decrease after NIV therapy.

Obesity has been proven to be the most common risk factor for OSAHS. Obese subjects usually respire with a lower compliance of the lung and chest wall. ${ }^{15,16}$ Breathing with such a respiratory system determines larger changes in intrathoracic pressure, and even generates positive intrathoracic pressure surrounding the lung while relaxed at the FRC level. Concomitantly, the high pleural pressure would cause tidal breathing to be initiated from low EELV where the lungs are less compliant and airways are prone to close on exhalation. ${ }^{17}$ Breathing at lower end-expiration volumes has been demonstrated to significantly influence upper-airway patency, through loss of tension of caudal traction in the pharyngealairway, making it more folded and leading to increased pharyngeal collapsibility.

In this study, the reactance (Xrs) at $5 \mathrm{~Hz}$ oscillatoryfrequencies measured and found to be significantly decreased in the obese OSAHS group and was found to strongly correlate with the severity of OSAS as defined by RDI and shows good predictive value for the diagnosis of OSAHS in obese snorers and also evident the usefulness of NIV. The X5 is a component of the out-of-phase air flow and pressure signal and is numerically a negative value that reflects the sum elastance or compliance of the respiratory system. X5 values that are more negative indicate reduced respiratory system compliance or increased lung elasticity recoil pressure. ${ }^{9-11}$ Our findings thus lead us to a conclusion that a narrowing of the upper airway due to obesity causes inspiratory resistive breathing, and leads to respiratory compliance reduction in OSAHS patients.

OSAS patients were optimally detected using the cut-off points of $-0.23 \mathrm{kPa}$.s. $\mathrm{L}^{-1}$ for $\mathrm{X} 5$ with a good sensitivity $77.7 \%$ and specificity of $79.4 \%$ and with a highly diagnostically accurate of 0.811 (95\% CI: 0.682-0.813). Among the predictors, R25 showed good PPV (76.9\%) and NPV (80\%) for the polysomnography screening of OSAHS.

\section{CONCLUSION}

In conclusion, IOS significantly correlate with the severity of OSAHS as defined by RDI. This study appears to indicate that the upper airway, or central airway may experience obstruction or collapse. Thus, reactance (X5) and resistance $\mathrm{R} 25$ measurements are related to the degree of airflow obstruction, which had a moderate sensitivity and specificity for screening OSAHS. Therefore, IOS measurements might be useful as a screening test for OSAHS during wakefulness.

\section{REFERENCES}

1. Stanchina ML, Malhotra A, Fogel RB, Trinder J, Edwards JK, Schory K, White DP. The influence of lung volume on pharyngeal mechanics, collapsibility, and genioglossus muscle activation during sleep. Sleep. 2003 Oct 1;26(7):851-856.

2. Bijaoui EL, Champagne V, Baconnier PF, Kimoff RJ, Bates HT. Mechanical properties of the lung and upper airways in patients with sleep-disordered breathing. Am J Respir Crit Care Med. 2002;165:1055-1061.

3. Bijaoui EL, Champagne V, Baconnier PF, Kimoff RJ, Bates J. Mechanical properties of the lung and upper airways in patients with sleep-disordered breathing. American journal of respiratory and critical care medicine. $2002 \mathrm{Apr}$ 15;165(8):1055-61.

4. Morgan BJ, Reichmuth KJ, Peppard PE, Finn L, Barczi SR, Young T, Nieto FJ. Effects of sleep-disordered breathing on cerebrovascular regulation: a population-based study. American journal of respiratory and critical care medicine. 2010 Dec 1;182(11):1445-52.

5. Yaggi HK, Concato J, Kernan WN, Licntman JH, Brass LM, Mohsemin V. Obstructive sleep apnea as a risk factor for stroke and death. N Engl J Med. 2005 Nov;353:20342041. 
6. Verin E, Tardif C, Portier F, Similowski T, Pasquis P, Muir JF. Evidence for expiratory flow limitation of extrathoracic origin in patients with obstructive sleep apnoea. Thorax. 2002 May 1;57(5):423-428.

7. Van Meerhaeghe A, Delpire P, Stenuit P, Kerkofs N. Operating characteristics of the negative expiratory pressure technique in predicting obstructive sleep apnoea syndrome in snoring patients. Thorax. 2004;59(10):883-888.

8. Van Noord JA, Wellens W, Clarysse I, Cauperghs M, Vande Woestijne KP, Demedts MG. Total respiratory resistance and reactance in patients with upper airway obstruction. Chest. 1987 Sep;92(3):475-480.

9. Owens RL, Malhotra A, Eckert DJ, White DP, Jordan AS. The influence of end-expiratory lung volume on measurements of pharyngeal collapsibility. J Appl Physiol. 2010 Feb;108(2):445-451.

10. Tagaito Y, Isono S, Remmers JE, Tanaka A, Nishino T. Lung volume and collapsibility of the passive pharynx in patients with sleep-disordered breathing. J Appl Physiol. 2007 Oct;103(4):1379-1385.

11. Lorino AM, Hamoudi K, Lofaso F, Dahan E, Mariette C, Harf A, Lorino $\mathrm{H}$. Effects of continuous negative airway pressure on lung volume and respiratory resistance. J Appl Physiol. 1999 Aug 1;87(2):605-610. [PubMed]
12. Abdeyrim A, Zhang YP, Li NF, Zhao MH, Wang YH, Yao $\mathrm{XU}$. Impact of obstructive sleep apnea on lung volumes and mechanical properties of the respiratory system in overweight and obese individuals. BMC Pulmonary Medicine. 2015;15:76.

13. American Academy of Sleep Medicine .International Classification of Sleep Disorders. 3. Darien, IL: American Academy of Sleep Medicine; 2014.

14. Oostveen E, MacLeod D, Lorino H, Farre R, Hantos Z, Desager K, Marchal F. The forced oscillation technique in clinical practice:methodology, recommendations and future developments. EurRespir J. 2003 Dec 1;22(6):1026-1041.

15. Suratt PM, Wilhoit SC, Hsiao HS, Atkinson RL, Rochester DF. Compliance of chest wall in obese subjects. J Appl Physiol. 1984 Aug 1;57(2):403-407. [PubMed]

16. Pelosi P, Croci M, Ravagnan I, Vicardi P, Gattinoni L. Total respiratory system, lung, and chest wall mechanics in sedated-paralyzed postoperative morbidly obese patients. Chest. 1996 Jan 1;109(1):144-151.

17. Behazin N, Jones SB, Cohen RI, Loring SH. Respiratory restriction and elevated pleural and esophageal pressures in morbid obesity. J Appl Physiol. 2009 Nov 12;108(1):212218. 